IZADP No. 1945

The Substitutability of Labor of Selected Ethnic Groups in the US Labor Market

Martin Kahanec

J anuary 2006 


\title{
The Substitutability of Labor of Selected Ethnic Groups in the US Labor Market
}

\author{
Martin Kahanec \\ IZA Bonn
}

\section{Discussion Paper No. 1945 \\ January 2006}

\author{
IZA \\ P.O. Box 7240 \\ 53072 Bonn \\ Germany \\ Phone: +49-228-3894-0 \\ Fax: +49-228-3894-180 \\ Email: iza@iza.org
}

\begin{abstract}
Any opinions expressed here are those of the author(s) and not those of the institute. Research disseminated by IZA may include views on policy, but the institute itself takes no institutional policy positions.

The Institute for the Study of Labor (IZA) in Bonn is a local and virtual international research center and a place of communication between science, politics and business. IZA is an independent nonprofit company supported by Deutsche Post World Net. The center is associated with the University of Bonn and offers a stimulating research environment through its research networks, research support, and visitors and doctoral programs. IZA engages in (i) original and internationally competitive research in all fields of labor economics, (ii) development of policy concepts, and (iii) dissemination of research results and concepts to the interested public.
\end{abstract}

IZA Discussion Papers often represent preliminary work and are circulated to encourage discussion. Citation of such a paper should account for its provisional character. A revised version may be available directly from the author. 


\section{ABSTRACT \\ The Substitutability of Labor of Selected Ethnic Groups in the US Labor Market ${ }^{*}$}

This paper investigates the substitutability of labor of selected ethnic groups in the US labor market. In the generalized Leontief framework, the analysis of US census-based data reveals that labor of non-White ethnic groups is complementary to that of White ethnic group. This finding supports the view that the negative relationship between the relative earnings of an ethnic group and its relative size is a labor market phenomenon. Moreover, it implies that ethnic diversity of labor force has positive effects on aggregate output. While the estimated elasticities of complementarity are relatively small, they are shown to generate significant effects, given the very uneven distribution of ethnic groups across local labor markets, as resulting from long-run migration patterns.

JEL Classification: J15, J24

Keywords: $\quad$ substitutability, elasticity of substitution, ethnic group, labor market

Corresponding author:

Martin Kahanec

IZA

P.O. Box 7240

53072 Bonn

Germany

Email: kahanec@iza.org

\footnotetext{
*I thank Jan van Ours, Sjak Smulders, Joshua Angrist, Frederic Vermeulen, Dimitris Pavlopoulos, and the participants of various seminars at CentER, Tilburg University, and IZA Bonn for helpful comments on the earlier drafts of this paper. All remaining errors are mine. Financial support from Volkswagen Foundation for the IZA project on "The Economics and Persistence of Migrant Ethnicity" is gratefully acknowledged.
} 


\section{Introduction}

Two main objectives have driven economists to study the nature of labor market competition between different ethnic groups. ${ }^{1}$ First, we strive to understand the differences in the economic status of various ethnic groups in the labor market. Second, we would like to provide sound assessment of labor market and immigration policies that aim at objectives concerning interaction of ethnic groups in the labor market. Such objectives include reduction of inter-ethnic inequality, elimination of social exclusion of some ethnic groups, or eradication of labor market discrimination.

The substitutability of labor of different ethnic group is the key characteristic of the ethnically diverse labor market. ${ }^{2}$ Unsatisfactorily, so far there is no consensus in the literature on the substitutability of labor of different ethnic groups. Grant and Hamermesh (1981) studied the substitutability of youths, White women, White men, Black adults, and capital in production, estimating a translog econometric model over 67 standard metropolitan statistical areas (SMSAs). They found that Black adults were substitutes for White men and complements to White women and youths in production, although the statistical significance of the relationships of complementarity was low. In a similar framework, Grossman (1982) investigated the substitutability of natives and immigrants in production to find that both foreign-born workers and second-generation native workers were substitutes for native workers. Borjas (1983) utilized Diewert's (1971) generalized Leontief approximation to a production function to study substitutability of Black, Hispanic, and White male workers. Borjas suggested that Black male workers might be substitutes for White male workers and found evidence for complementarity between Hispanic and White male workers. Using a similar methodology, Borjas (1987)

\footnotetext{
${ }^{1}$ Ethnic group is defined as a particular group of people who share socio-cultural characteristics such as culture, religion, language, history, beliefs, customs, values, and morals that make them distinct from the rest of the population in their habitat.

${ }^{2}$ In this study I do not distinguish the various possible sources of imperfect substitutability of labor of different ethnic groups. Such sources include historical reasons and socio-cultural differences as in Hofstede (1980) and Borjas (1994), organization of social interaction in human capital acquisition as in Kahanec (2004), or constraints imposed upon some ethnic groups by the society as in the discrimination literature based on Becker (1957) and Arrow (1972a, 1972b, 1973, 1998). That ethnic groups tend to specialize in certain types of jobs and education has been discussed by e.g. Altonji and Blank (1998:3153) and Chiswick (1988), respectively.
} 
examined the substitutability of White, Black, Hispanic, and Asian male workers by immigrant status over 84 SMSAs. In this study he found that all immigrant groups were substitutes for native Whites; however, this evidence was not robust with respect to endogeneity of labor supply. Furthermore, he found that Black natives were substitutes for White natives, but did not find such evidence for Hispanic and Asian natives. These studies are summarized in Table 1 in the Appendix.

The inconclusiveness of this evidence is startling. Several results point at substitutability, but some suggest that labor of different ethnic groups is complementary. Clearly, substitutability and complementarity have very different effects on the labor market. To illustrate this, if labor of ethnic groups A and B is complementary in production, increase in the relative number of workers of ethnic group A increases the marginal product of workers from ethnic group B and vice versa. ${ }^{3}$ As a consequence, assuming that changes in marginal products are reflected in wages, relative earnings of workers from group A vis-à-vis workers from group B decrease in the relative number of workers from group A, ceteris paribus. In contrast, if labor of ethnic groups A and B is substitutable, increase in the relative number of workers of group A increases their relative wages vis-à-vis White workers. These distributional consequences of imperfect substitutability of labor of different ethnic groups make the question of substitutability of labor of different ethnic groups highly relevant.

The general observation that the elasticities reported in the abovementioned literature are numerically small does not undermine the relevance of this question. The reason is that even small elasticities may generate significant effects when the variation of ethnic composition of the labor force is high. And it is very high indeed. To wit, in the US, the percentage of Blacks is about 33 times larger in the $75^{\text {th }}$ percentile than in the $25^{\text {th }}$ percentile school district. Similarly, there are about 10 times more Asians and 22 times more Hispanic per one hundred inhabitants in the respective $75^{\text {th }}$ and $25^{\text {th }}$ percentile

\footnotetext{
${ }^{3}$ There is robust empirical evidence, including the studies by Blalock (1956, 1957), Heer (1959), Brown and Fuguitt (1972), Frisbie and Neidert (1977) and Tienda and Lii (1987), that non-White individuals in regions with a higher non-White share earn relatively less than non-White individuals in regions with a smaller non-White share. This evidence is summarized in Kahanec (2004).
} 
school districts. ${ }^{4}$ Such highly uneven distribution of ethnic groups across US local labor markets, mainly resulting from long-run migration patterns, is argued below to explain a significant share of interethnic earnings differential.

This study contributes to the substitutability debate discussed above by shedding light on the question whether labor of the largest non-White ethnic groups and the White ethnic group in the US is complementary or substitutable in production. The practical contribution is twofold. First, we learn about the direction of the effects of increasing presence immigrants and their descendants in the US labor market on earnings inequality. Second, we learn about the effects of ethnic diversity of the labor force on aggregate output. To achieve this objective, this study investigates a US Census-based dataset described below that offers two main advantages. First, it permits a relatively fine partition of the labor force into ethnic groups, such that we can study labor market interaction of five non-White and the White ethnic groups. Second, this dataset permits a relatively large variation of the key explanatory variable - the ratios of labor supplies of different ethnic groups. In particular, given that the baseline unit of observation in the dataset (and of this study) is the school district, this dataset has information about more than 14,000 local labor markets. ${ }^{5}$

Previewing the main results of this study, I empirically establish that the largest US nonWhite ethnic groups are complementary to the White ethnic group in production. This finding is robust with respect to a number of alternative specifications of the unit of study, sample, and production technology. Given this result, this study suggests that labor market forces disadvantage members of those ethnic groups in terms of their (relative) earnings per efficiency unit of their labor that form a large proportion in a local labor market. In addition, it suggests that ethnic diversity in the labor market exhibits complementarities that positively affect aggregate output.

\footnotetext{
${ }^{4}$ Percentiles in this section refer to ranking of school districts according to the respective percentage of non-White population.

${ }^{5}$ The key question concerning the choice of the unit of observation is what the proper geographic definition of the local labor market is. Sensitivity analysis reveals that the results of this study are robust in this respect. See the discussion below.
} 
To establish this result, I proceed in a number of steps. In the following two sections I develop the baseline analytical framework and provide the description of the data. In the next section I outline the estimation methods and establish the main results. Then I test the validity of the main results with respect to some alternative explanations and specifications. In the final analytical section I study the substitutability issue in the constant elasticity of substitution framework and estimate this elasticity. Then I conclude and suggest issues for further research.

\section{The Model}

To investigate the production relationships among non-White and White ethnic groups, I assume a generalized Leontief production function:

$$
C=\sum_{j} \sum_{i} \beta_{i j}\left(X_{i} X_{j}\right)^{1 / 2}
$$

where $C$ stands for output, $X_{i}$ and $X_{j}$ are, respectively, the quantities of labor inputs of ethnic groups $i$ and $j$ in the labor market and $\beta_{i j}$ is the technology parameter, which is restricted such that $\beta_{i j}=\beta_{j i}{ }^{6}$ Labor inputs $i$ and $j$ are complements whenever $\beta_{i j}>0$ and substitutes whenever $\beta_{i j}<0$. Assuming that firms in the labor market operate in a perfectly competitive industry, the system of labor demands derived from the production function (1) is:

$W_{i}=\beta_{i i}+\sum_{i \neq j} \beta_{i j}\left(X_{j} / X_{i}\right)^{1 / 2}$,

where $W_{i}$ is the wage of individuals from group $i$. This system of labor demands is particularly useful for empirical analysis, as it is linear in parameters $\beta_{i j}$ and thus can be estimated by conventional least squares methods. The interpretation of $\beta_{i j}$ is also straightforward: $\beta_{i j}$ is positive (negative) and the wage of group $i$ increases (decreases) in the number of type- $j$ individuals per type-i individual whenever type- $j$ and type- $i$

\footnotetext{
${ }^{6}$ Generalized Leontief production function is a second order approximation to any arbitrary production function and the parametric restriction should be seen as an integral part thereof. See Diewert (1971) for a discussion of the properties of this production function and Borjas (1987) for a note on the choice between the generalized Leontief and translog functional forms.
} 
individuals are complements (substitutes) in production. Thus, according to the system of labor demands (2), the wage of members of ethnic group $i$ is affected by the numbers of members of other groups per member of group $i, X_{j} / X_{i}$.

A useful transformation of the coefficient $\beta_{i j}$ is the one that links it to the Hicks partial elasticity of complementarity: $e_{i j}=C C_{i j} / C_{i} C_{j}$, where $C_{i}=\partial C / \partial X_{i} \quad$ and $C_{i j}=\partial^{2} C / \partial X_{i} \partial X_{j} \cdot{ }^{7}$ Namely, it can be shown that under the Generalized Leontief production function the elasticities of complementarity are given by:

$e_{i j}=\frac{\beta_{i j}}{2\left(s_{i} s_{j} W_{i} W_{j}\right)^{1 / 2}}$ for $i \neq j$

and

$e_{i i}=\frac{\beta_{i i}-W_{i}}{2 s_{i} W_{i}}$ for $i=j$,

where $s_{i}=W_{i} X_{i} / C$ is the relative share of income accruing to labor input $i$. The Hicks elasticity of complementarity measures the effect of a change in the relative supply of input $j$ on the relative price of input $i$, holding the quantities and marginal costs of other inputs constant. A useful property of the elasticity of complementarity is that $\frac{d \ln \left(W_{i}\right)}{d \ln \left(X_{j}\right)}=s_{j} e_{i j}$.

In consequence, these elasticities completely describe the changes in wages resulting from changes in supplies of labor inputs for any given share of income accruing to the respective labor input.

Estimation of the demand system (2) involves three major econometric issues. First, labor force is not necessarily homogenous across labor markets. Certainly, members of group $i$ may earn different average wages in some regions than in others not as a result of regional differences in relative supplies of labor inputs, but as a result of variation of their average skills. To solve this issue, I adopt an analogue of the technique customary in the

\footnotetext{
${ }^{7}$ See Hicks (1970).
} 
literature. ${ }^{8}$ In particular, I assume that the average earnings of members of group $i$ in labor market $n, E_{i, n}$, depend on (i) the market-determined wage for the average member of group $i$ in labor market $n, W_{i, n}$, and (ii) the difference $f_{i, n}$ between the average skill level of members of group $i$ in labor market $n$ and the average skill level of all members of group $i$. This difference, $f_{i, n}$, is treated as a fixed effect such that, formally, a representative member of group $i$ from labor market $n$ earns wage $E_{i, n}=W_{i, n}+f_{i, n}$. It is assumed that $f_{i, n}=Z_{i, n}+\varepsilon_{i, n}$, where $Z_{i, n}$ is the vector of observable characteristics of individuals of type $i$ in labor market $n$ and $\varepsilon_{i, n}$ is the respective random uncorrelated error. Assuming that in each labor market wages are determined according to the demand system (2), it follows that

$$
E_{i, n}=\beta_{i i}+\sum_{i \neq j} \beta_{i j}\left(X_{j, n} / X_{i, n}\right)^{1 / 2}+\beta_{i} Z_{i, n}+\varepsilon_{i, n},
$$

which is the specification of the system of labor demands used throughout the paper.

Second, the relative supplies of labor inputs, $X_{j, n} / X_{i, n}$, may be endogenous. Therefore, while in the baseline analysis of this paper the assumption of inelastic labor supply is adopted, I extend the analysis to more complex supply conditions in Section 5.1. In particular, I adopt the conventional approach to this problem and address the endogeneity issue in the instrumental variable framework. Finally, although the focus of the analysis is on labor inputs, other inputs such as capital, land, and technology enter production. In the literature, this issue has often caused difficulties. Scholars who attempt to account for capital admit that the measures of capital that they use are unsatisfactory or of limited use. ${ }^{9}$ Land and technology have not been, to my knowledge, addressed in this context at all. Despite the limitations given by the available data, in Section 5.3 I address this issue and test the robustness of the predictions of this paper using the degree of urbanization and farming as indicators of capital and land utilization. The analysis is based on the assumption that urbanization (farming) is positively (negatively) related to capital

\footnotetext{
${ }^{8}$ See Borjas (1983) and Borjas (1987).

${ }^{9}$ See e.g. Grant and Hamermesh (1981), Grossman (1982), Borjas (1983), and Borjas (1987).
} 
utilization and technological advancement and negatively (positively) to land utilization in production.

\section{Data}

The empirical analysis is conducted on the dataset that contains data about 14,405 school districts of the US, as compiled in the Census 2000 School District Tabulation (STP2) by the National Center for Education Statistics (NCES) of the US. ${ }^{10}$ The auxiliary data from the year 1990 are compiled from the SDDB-School District Database (NCES 95-705) as available at the National Bureau for Economic Research. ${ }^{11}$ This dataset contains economic and demographic information about the White (non-Hispanic) ethnic group, hereafter "White," and five non-White ethnic groups: (i) Black or African American, hereafter "Black", (ii) American Indian or Alaska native, hereafter "American Indian," (iii) Asian, (iv) Native Hawaiian or other Pacific Islander, hereafter "Pacific Islander," and (v) Hispanic or Latino. Two points are worth mentioning in regard of this particular partition of the labor force. First, it covers most of the US labor force as identified in the 2000 Census. ${ }^{12}$ Second, this partition is appropriate in the light of the main interest of this study: the substitutability of labor of different ethnic and racial groups. In particular, although further sub-partitions of workers of different ethnicities based on age, immigrant status, or gender certainly deserve further research, they are not the focus of this study. ${ }^{13}$

The school district, a special purpose administration district in the US in which public schools are administered, was chosen as the baseline unit of observation. School districts reflect the organization of social and economic life of the population and thus provide a reasonable geographical representation of the local labor market. Nevertheless, it is necessary to evaluate sensitivity of the results of this study with respect to the choice of

\footnotetext{
${ }^{10}$ http://nces.ed.gov/surveys/sdds/c2000.asp.

${ }^{11} \mathrm{http} / / / \mathrm{www}$. nber.org/sddb/.

${ }^{12}$ The two remaining groups not covered here are "Some other race" and "Two or more races".

${ }^{13}$ See Grossman (1982) and Borjas (1987) for a partition based on immigrant status, Grant and Hamermesh (1981) and Borjas (1987) for a partition based on gender, and Grant and Hamermesh (1981) for a partition based on age. The data does not permit partition by immigrant status, age, or any other. It does permit partition by gender (and race), however. Supplementary investigation shows that the main predictions of this study are robust with respect to restricting the analysis to men.
} 
the geographical definition of the local labor market. The robustness check that was conducted in this matter involved estimation of the model only for school districts with relatively large population, thus more similar to SMSAs. It turned out that the main results reported below are robust with respect to such exercise. ${ }^{14}$

For this study, the most relevant information in the NCES dataset involves earnings and income, educational attainment, employment status and time worked, and age structure of members of each racial and ethnic group mentioned above. The main statistics for the key variables are depicted in Tables 2 to 4 . As one can see, the average school district has 7,768 full-time workers of all races combined, while the median school district has 2,325 full-time workers. The relatively large discrepancy is due to a number of relatively large districts, i.e. 113 school districts have full-time working populations above 100,000 and 6 out of these are above 500,000, but in more than 91 percent of school districts the number of full-time workers is between 100 and 30,000. Table 2 also reveals very large discrepancies between mean and median numbers of non-White full-time workers, which suggests concentration of non-White ethnic groups in subsets of school districts.

Table 2: Numbers of full-time workers, by race.

\begin{tabular}{|l|c|c|c|c|}
\hline \multicolumn{1}{|c|}{ Race } & Min & Max & Mean & Median \\
\hline All races & 8 & $2,313,825$ & 7,768 & 2,325 \\
\hline White & 0 & 922,630 & 4,944 & 1,685 \\
\hline Black & 0 & 528,105 & 1,091 & 55 \\
\hline American Indian & 0 & 11,735 & 66 & 14 \\
\hline Asian & 0 & 228,700 & 457 & 24 \\
\hline Pacific Islanders & 0 & 27,815 & 66 & 10 \\
\hline Hispanic or Latino & 0 & 630,760 & 855 & 45 \\
\hline
\end{tabular}

Note: Computed for school districts with positive total population $(14,375)$.

Table 3 depicts that, as concerns median earnings, each non-White ethnic group earns less than the White ethnic group. This is also true for average earnings, with the exception of Asian workers. The reason that Asians on average earn more and in the median school district less than Whites is also apparent in Table 3: the share of school districts with median earnings above 100,000 US dollars per year is by far the largest for

\footnotetext{
${ }^{14}$ Results available upon request. The robustness check involved sample reductions such that the analysis was limited to school districts with population larger than 30, 50, and 100 thousand inhabitants.
} 
the Asian ethnic group. As concerns the relative standing of the non-White ethnic groups vis-à-vis the White ethnic group, non-White people earn between 33.9 percent less and 2.8 percent more and between 31.8 percent and 2.5 percent less than White individuals, measured by mean and median earnings, respectively.

\begin{tabular}{|c|c|c|c|c|}
\hline \multicolumn{5}{|c|}{ Table 3: Median earnings of full time workers, by race. } \\
\hline \multirow[t]{2}{*}{ Race } & \multicolumn{2}{|c|}{$\begin{array}{c}\text { Percent of school districts } \\
\text { with yearly median } \\
\text { earnings }\end{array}$} & \multicolumn{2}{|c|}{ Median earnings } \\
\hline & $<2,500$ & $\geq 100,000$ & Mean & Median \\
\hline White & 0.01 & 0.15 & 36,612 & 34,768 \\
\hline Black & 0.03 & 0.63 & 28,255 & 27,589 \\
\hline American Indian & 0.25 & 0.66 & 27,125 & 25,661 \\
\hline Asian & 0.14 & 2.15 & 37,660 & 33,900 \\
\hline Pacific Islanders & 0.03 & 0.33 & 29,714 & 28,572 \\
\hline Hispanic or Latino & 0.13 & 0.53 & 24,196 & 23,729 \\
\hline
\end{tabular}

Table 4: Percentages of people above 25 with university education.

\begin{tabular}{|l|c|c|c|c|}
\hline \multirow{2}{*}{ Race } & \multicolumn{2}{c|}{$\begin{array}{c}\text { Graduate or professional } \\
\text { degree }\end{array}$} & \multicolumn{2}{c|}{ Bachelor's degree } \\
\cline { 2 - 5 } & Mean & Median & Mean & Median \\
\cline { 2 - 5 } & 10.04 & 8.19 & 17.41 & 16.04 \\
\hline White & 4.89 & 4.23 & 9.63 & 8.67 \\
\hline Black & 4.59 & 0.00 & 8.31 & 1.97 \\
\hline American Indian & 15.99 & 12.92 & 26.06 & 25.18 \\
\hline Asian & 6.48 & 0.00 & 11.23 & 0.00 \\
\hline Pacific Islanders & 3.86 & 3.39 & 7.33 & 6.36 \\
\hline Hispanic or Latino & $\begin{array}{l}\text { Note: Computed for school districts with positive total population (14,375). Mean and median } \\
\text { weighted by respective populations. }\end{array}$ \\
\hline
\end{tabular}

Finally, in Table 4 one can observe that some of the variation of earnings is due to variation in educational levels. In particular, each non-White ethnic group has a lower educational level than the White ethnic group, measured by mean and median percentages of respective populations with graduate and undergraduate degrees. The only exception are Asians, who attain a higher educational level than Whites. The 
extraordinarily high educational achievement of Asians appears to be the explanation of why their earnings more or less match the earnings of Whites.

A note concerning the numbers of observations is due before I proceed to the results. While there are 14,375 school districts with positive total population, in the analysis below observations are lost due to two main reasons. First, a large number of observations are lost as a result of the structure of the model. Namely, estimation of a simultaneous equation model with each equation representing one social group implies that one can estimate the system only for those school districts that contain all these social groups. Second, a relatively small number of observations contain missing information, which precludes their inclusion in the analysis. To illustrate, in the baseline model of the next section that involves the White ethnic group as well as all five nonWhite ethnic groups, the first restriction reduces the number of school districts to 2,009. Further 66 observations are lost due to missing information, resulting in 1,943 observations included in the baseline model.

Table 5: Numbers and median earnings of full-time workers, by race. Districts with all social groups present.

\begin{tabular}{|l|c|c|c|c|}
\hline & \multicolumn{2}{|c|}{ Number of workers } & \multicolumn{2}{c|}{ Median earnings } \\
\hline \multicolumn{1}{|c|}{ Race } & Mean & Median & Mean & Median \\
\hline White & 19,623 & 9,700 & 38,312 & 36,562 \\
\hline Black & 3,848 & 485 & 28,537 & 27,883 \\
\hline American Indian & 195 & 74 & 27,746 & 26,516 \\
\hline Asian & 1,789 & 270 & 36,715 & 33,514 \\
\hline Pacific Islanders & 84 & 14 & 29,790 & 28,572 \\
\hline Hispanic or Latino & 4,420 & 760 & 24,065 & 23,750 \\
\hline
\end{tabular}

Note: Computed for the 1,949 school districts included in the analysis of Section 4.4. Mean and median weighted by respective populations of workers. In US dollars.

To understand the consequences of such reductions of the sample, Table 5 lists the basic statistics of the sample of the baseline model. As one can observe comparing Table 5 to Tables 2 and 3, sample reduction has a minor effect on mean and median earnings. The effect of sample reduction on mean and median numbers of full-time workers is one of a substantial increase of these numbers in the reduced sample. This is a natural consequence of the fact that sample reduction involved elimination of school districts that 
do not contain workers of each race, which are typically small school districts. Straightforward calculations show, however, that the relative numbers of non-White workers between the full sample and the reduced sample are much more similar than the absolute numbers.

Aggregation of ethnic groups into one (multiethnic) group increases the likelihood that at least one of the aggregated ethnic groups is present in a school district, thereby permitting inclusion of more school districts in the analysis. Dropping a relatively small ethnic group from the analysis has similar effect. To wit, aggregation of Asians and American Indians and omitting Pacific Islanders permits inclusion of 7,878 school districts. Aggregation of all non-White ethnic groups but the Pacific Islanders permits inclusion of as many as 13,335 school districts. ${ }^{15}$ In Section 5.2 I investigate this issue further and establish robustness of the results of the baseline analysis with respect to aggregation of non-White groups.

\section{Estimation Methods and Results}

The NCES dataset contains all the necessary information for the estimation of the econometric model (3). Labor input $X_{i, n}$ is defined as the number of full-time workers from group $i$ that are 15 years old and over. Correspondingly, median earnings of fulltime workers older than 15 is the baseline measure of $E_{i, n} \cdot{ }^{16}$ The vector of observable characteristics $Z_{i, n}$ comprises educational indicators measuring the percentages of adult members of group $i$ in school district $n$ with (i) high school diploma, (ii) some college but no degree, (iii) associate degree, (iv) bachelor’s degree, and (v) graduate or professional degree. $^{17}$ Besides these variables, regional dummies are included in every regression

\footnotetext{
${ }^{15}$ It turns out that these aggregations are statistically sensible. See Section 5.2.

${ }^{16}$ As an alternative specification, I re-estimated the model using the weighted average of median earnings of full-time and part-time workers as the explained variable and the ratios of the numbers of all non-White and White workers as the explanatory variable. The results were very similar to those obtained for full-time workers.

${ }^{17}$ Further analysis showed that inclusion of (i) relative numbers of workers that worked full-time less than the whole year by weeks worked and race or (ii) variables depicting the age structure of population by race in the vector $Z_{i, n}$ does not affect the main results, while reducing sample size significantly.
} 
throughout the analysis. ${ }^{18}$ The purpose of these dummy variables is to pick the effect of interstate variation in development, infrastructure, climate, and other factors outside the analyzed econometric model that possibly affect the distribution of earnings.

Econometric model (3) is estimated using the Zellner's seemingly unrelated regressions (SUREG) estimator, simultaneously imposing cross-equation technological restrictions $\beta_{i j}=\beta_{j i}$ implied by the generalized Leontief technology. Table 6 depicts the baseline estimates of the technological parameters. ${ }^{19}$ The main result, showing up in column (1), is that labor of each non-White ethnic group is complementary to that of the White ethnic group. This result is of substantial interest, as it supports the view that labor of non-White and White workers is imperfectly substitutable in the labor market. Furthermore, that non-White labor complements White labor in production suggests that ethnic diversity is beneficial in terms of aggregate output, ceteris paribus. And finally, this result is consistent with the empirical evidence of the direct relationship between White/nonWhite earnings gaps and the relative sizes of the respective non-White ethnic groups. In particular, complementarity implies that an increase in the relative size of a non-White ethnic group increases White earnings and decreases the earnings of this non-White ethnic group, holding the sizes of other ethnic groups and the aggregate size of the economy constant. As concerns the technological relationships among non-White ethnic groups, there appears to be a significant complementary relationship between Pacific Islanders and Asians, but all the other relationships are insignificant. As concerns the educational variables, they are significant and have expected signs and their magnitudes are ranked as expected. ${ }^{20}$

\footnotetext{
${ }^{18}$ These dummies represent school districts according to the US Census Bureau Classification: Mid-West East North, Mid-West West North, South Atlantic, South East Central, South West Central, North East New England, North East Mid-Atlantic, West Pacific except Hawaii, West Mountain, and Overseas (Hawaii and Puerto Rico). I joined Hawaii and Puerto Rico to construct the "Overseas" category.

${ }^{19}$ Technological parameters are reported only once; the restriction $\beta_{i j}=\beta_{j i}$ implies that the table of technological parameters is diagonally symmetric.

${ }^{20}$ In further analysis the parameters with educational variables are not reported.
} 
Table 6: Baseline estimates of the technological parameters.

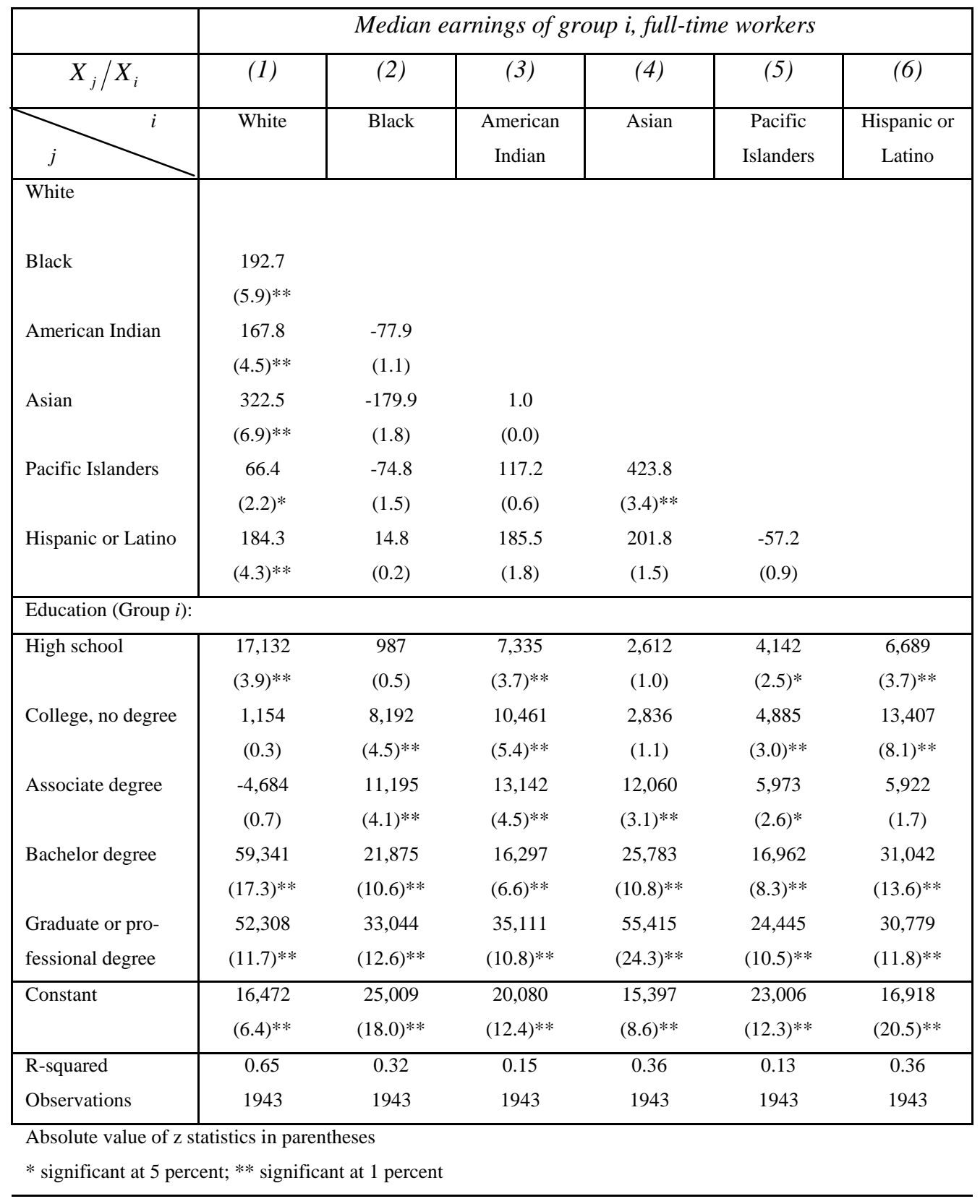

As concerns interpretation of the baseline results, it is instructive to derive the crosselasticities of complementarity $e_{i j}$ between the five non-White ethnic groups and the White ethnic group. Because these elasticities depend not only on the technological parameters $\beta_{i j}$ but also on $W_{i}$ and $s_{i}$, a decision has to be made about the values of $W_{i}$ and $s_{i}$ at which these elasticities are evaluated. Means and medians are the natural 
evaluation points. Table 7 summarizes cross-elasticities of complementarity $e_{i j}$ and elasticities of factor prices $s_{j} e_{i j}$ between non-White and White ethnic groups.

Table 7: Cross-elasticity of complementarity and elasticities of factor prices.

\begin{tabular}{|l|c|c|c|c|c|c|}
\hline & \multicolumn{2}{|c|}{$\begin{array}{c}\text { Cross-elasticity of } \\
\text { Complementarity }\end{array}$} & $\begin{array}{c}\text { Elasticity of factor prices } \\
\text { (Change in the wage of White } \\
\text { with respect to the quantity of } \\
\text { non-White labor) }\end{array}$ & $\begin{array}{r}\text { Elasticity of factor prices } \\
\text { (Change in the wage of non- } \\
\text { White with respect to the } \\
\text { quantity of White labor) }\end{array}$ \\
\cline { 2 - 8 } & Mean & Median & Mean & Median & Mean & Median \\
\hline Black & 0.0097 & 0.0173 & 0.0010 & 0.0006 & 0.0070 & 0.0155 \\
\hline American Indian & 0.0388 & 0.0406 & 0.0002 & 0.0002 & 0.0280 & 0.0362 \\
\hline Asian & 0.0186 & 0.0323 & 0.0012 & 0.0007 & 0.0134 & 0.0288 \\
\hline Pacific Islander & 0.0217 & 0.0343 & 0.0001 & $3.4 \mathrm{E}-5$ & 0.0156 & 0.0306 \\
\hline Hispanic or Latino & 0.0103 & 0.0155 & 0.0011 & 0.0007 & 0.0074 & 0.0139 \\
\hline
\end{tabular}

Note: Evaluated at mean and median $w_{i}$ and $s_{i}$ of the sample of Table 6, 1943 observations.

These estimates confirm the findings of the previous literature that although the elasticities are statistically significant, ${ }^{21}$ the effects are not numerically large. As a consequence, short-run migration, which involves relatively small changes in ethnic composition of labor supply in a local labor market, has relatively small effect on the relative earnings of different ethnic groups. ${ }^{22}$ When one compares school districts with markedly different ethnic composition of labor, as resulting from long-run migration patterns, the implied differences in earnings distributions may become substantial, however.

To illustrate, consider the $20^{\text {th }}$ percentile school district that has 9 and the $80^{\text {th }}$ percentile school district that has 199 Black per 1,000 White full-time workers. To estimate the difference in Black-White earnings differential between these school districts, let us use

\footnotetext{
${ }^{21}$ Concerning the significance levels of the respective technological coefficients from Table 6.

${ }^{22}$ Given the variation of the earlier results, direct comparison is almost impossible. Among those results in the previous literature that establish complementarity of non-White and White labor, Borjas (1983) finds the elasticity of complementarity between Hispanic and White labor of about 0.0234 , thus slightly higher than my result of 0.0155. Grant and Hamermesh (1981) establish somewhat higher elasticities of factor prices for the substitutability of Black workers with White female workers, but their results were not significant.
} 
the estimate of the technological parameter from Table 6. In addition, assume that relative labor input supplies are the only determinants of earnings and that, net of their influence, workers earn the median earnings of their social group. Given these simplifications, it turns out that Black workers earn about 6.1 percent more $(29,687$ vs. 27,990 US dollars per annum) and White workers about 0.2 percent less (34,787 vs. 34,868 US dollars per annum) in the $20^{\text {th }}$ percentile than in the $80^{\text {th }}$ percentile school district. $^{23}$ This implies a substantial reduction of the Black-White earnings differential from 6,877 to 5,099 US dollars per year, that is, by about a quarter. This example illustrates that even if the effects of migration over the short run on earnings are perhaps numerically unimportant, long-run migration patterns and the resulting changes in the ethnic composition of labor supply matter substantially for the distribution of earnings.

\section{Robustness of the Baseline Results}

\subsection{Supply Side}

While in the previous section the assumption of inelastic labor supply was adopted, it is possible that labor supply responds to wages. People may decide to migrate for better jobs, to work more (or less) in response to a higher wage, or it may be that people with higher wages can afford better medical care and thus be absent from work less often. Whenever any of such possibilities is operative, labor inputs are endogenous and, as a result, the baseline estimates of Table 6 are biased. To account for the possibility of endogeneity of labor inputs, the instrumental variable framework is adopted in this section. In particular, I adopt the three-stage least square method (3SLS) to estimate the technological parameters of the system of demand equations involved in the econometric model (3). As above, the technological constraints $\beta_{i j}=\beta_{j i}$ are imposed.

The respective ratios of population sizes of different ethnic groups from the year 1990 are used to instrument $X_{j, n} / X_{i, n}$. The assumption that is made here is that these past ratios are related to current earnings through current ratios of labor supplies, $X_{j, n} / X_{i, n}$, but not

\footnotetext{
${ }^{23}$ Similar computations using the estimated elasticities of factor prices lead to a variation of even greater magnitude, leading to the estimates of 32.7 and 1.3 percent, respectively.
} 
directly. This assumption of indirect relationship is capturing the idea that past presence of a non-White in a school district attracts immigration of similar people through social relations, that people have incentives to remain in the place of their birth to avoid the costs involved in relocation, and that larger populations contain more workers. ${ }^{24}$

\begin{tabular}{|c|c|c|c|c|c|c|}
\hline & \multicolumn{6}{|c|}{ Median earnings of group i, full-time workers } \\
\hline$X_{j} / X_{i}$ & (1) & (2) & (3) & (4) & (5) & (6) \\
\hline $\mathrm{Y}_{j}{ }^{i}$ & White & Black & $\begin{array}{c}\text { American } \\
\text { Indian }\end{array}$ & Asian & $\begin{array}{c}\text { Pacific } \\
\text { Islanders }\end{array}$ & $\begin{array}{c}\text { Hispanic or } \\
\text { Latino }\end{array}$ \\
\hline White & & & & & & \\
\hline Black & $\begin{array}{c}195.3 \\
(4.5)^{* *}\end{array}$ & & & & & \\
\hline American Indian & $\begin{array}{c}241.9 \\
(3.7)^{* *}\end{array}$ & $\begin{array}{c}-122.4 \\
(1.3)\end{array}$ & & & & \\
\hline Asian & $\begin{array}{c}314.8 \\
(4.8)^{* *}\end{array}$ & $\begin{array}{l}-327.5 \\
(2.4)^{*}\end{array}$ & $\begin{array}{l}185.8 \\
(1.1)\end{array}$ & & & \\
\hline Pacific Islanders & $\begin{array}{l}13.6 \\
(0.2)\end{array}$ & $\begin{array}{l}-86.1 \\
(1.3)\end{array}$ & $\begin{array}{l}-7.3 \\
(0.0)\end{array}$ & $\begin{array}{l}206.2 \\
(1.1)\end{array}$ & & \\
\hline Hispanic or Latino & $\begin{array}{c}242.4 \\
(4.0)^{* *}\end{array}$ & $\begin{array}{l}-70.4 \\
(0.7)\end{array}$ & $\begin{array}{l}92.2 \\
(0.6)\end{array}$ & $\begin{array}{c}-121.8 \\
(0.6)\end{array}$ & $\begin{array}{l}-79.5 \\
(0.8)\end{array}$ & \\
\hline Constant & $\begin{array}{l}19,241 \\
(6.6)^{* *}\end{array}$ & $\begin{array}{c}23,450 \\
(15.5)^{* *}\end{array}$ & $\begin{array}{l}17,914 \\
(8.4)^{* *}\end{array}$ & $\begin{array}{l}17,805 \\
(8.4)^{* *}\end{array}$ & $\begin{array}{l}25,892 \\
(8.1)^{* *}\end{array}$ & $\begin{array}{c}17,562 \\
(18.8)^{* *}\end{array}$ \\
\hline R-squared & 0.65 & 0.33 & 0.15 & 0.36 & 0.10 & 0.35 \\
\hline Observations & 1563 & 1563 & 1563 & 1563 & 1563 & 1563 \\
\hline
\end{tabular}

The most important result of this analysis, summarized in Table 8 , is that the signs and magnitudes of the coefficients remain very similar to those of Table $6 .^{25}$ To wit, comparing these two tables, the coefficient in column (1) for the Black ethnic group changes from 192.7 to 195.3 and for the Asian non-White from 322.5 to 314.8. In other words, these coefficients almost do not differ whether estimated using the SUREG or

\footnotetext{
${ }^{24}$ The existence of such links is confirmed by the (non-reported) first-step regressions of the 3SLS analysis, where the sets of instruments are statistically significant in each first-step regression. Reduced-form estimation shows that the relationships between explained variables and the exogenous variables are significant and have expected signs.

${ }^{25}$ Note that Table 7 contains about 380 observations less than Table 5. This loss results from missing observations for the instruments.
} 
3SLS method. Coefficients with other non-White ethnic groups even somewhat increase in magnitude, in favor of the White/non-White complementarity hypothesis. While the coefficient with Pacific Islanders loses significance, its sign remains positive. These results suggest that the possible endogeneity bias is in general insignificant and the results of the baseline analysis of Table 6 are robust in this respect. In other words, it is the demand side that drives the relationship between relative numbers of workers and their earnings.

\subsection{Aggregation}

As mentioned above, one of the issues with estimation of the system of demand equations involved in econometric model (3) is that the number of observations is limited by the restriction that only school districts that contain workers of each ethnicity can be included in the analysis. In this section I investigate this issue. In general, from the previous sections it appears that each non-White ethnic group is complementary to the White ethnic group, with the exception of the Pacific Islanders, who seems not to have a significant effect on White earnings. To evaluate the validity of these observations, I test two hypotheses concerning coefficient restrictions. First, I test the hypothesis that the coefficients $\beta_{i j}$ for $j$ representing American Indians and Asians and $i$ representing Whites, Blacks, and Hispanic or Latino are equal and that the corresponding coefficients for $j$ representing Pacific Islanders is zero. The test of this hypothesis in the SUREG model of Table 6 yields $\chi^{2}=14.88$, thus not rejecting the null hypothesis at 0.01 confidence level. In the 3SLS model of Table 8, this hypothesis is not rejected at any conventional confidence level, yielding the test statistics $\chi^{2}=6.38$. Second, similarly, I test the hypothesis that the coefficients $\beta_{i j}$ for $i$ representing the White ethnic group are equal for all non-White ethnic groups $j$ except for the coefficient with Pacific Islanders that is zero. The test of this hypothesis in the SUREG framework yields $\chi^{2}=12.86$, which is insignificant at the 0.01 confidence level. Testing the same hypothesis in the 3SLS framework yields $\chi^{2}=2.50$ which is insignificant at any conventional confidence level. 
Given these results, I impose the abovementioned parametric restrictions one by one on the model and treat the respective non-White ethnic groups as one homogeneous group in the labor market. Aggregation of Asians and American Indians permits inclusion of 7,878 school districts in the analysis, that is, almost four times as many as in the baseline model. The model is estimated using the Zellner's SUREG estimator with the properly defined parametric constraint $\beta_{i j}=\beta_{j i}$. The results are summarized in Table 9. As one can observe, the main result remains intact: non-White ethnic groups are complementary to the White ethnic group in the labor market. The magnitudes also remain very similar to the baseline estimates of Table 6 and the 3SLS estimates of Table 8. The aggregate of Asians and American Indians is also complementary to Whites, although the magnitude of this effect and its significance is not very large. Interestingly, this aggregate appears to be complementary to Blacks.

Table 9: Aggregation.

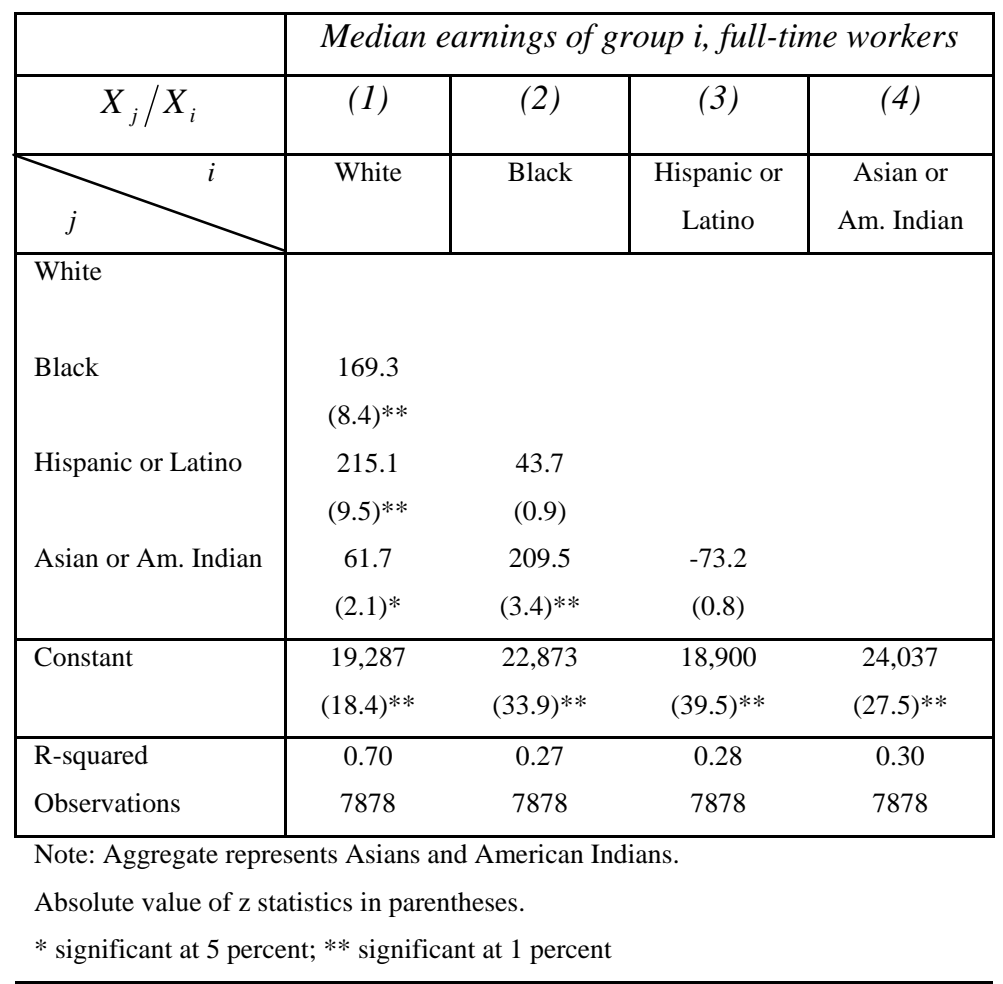

Concerning the second parametric restriction, aggregation of all non-White ethnic groups but Pacific Islanders, who are dropped from the analysis, permits inclusion of as many as 
13,335 school districts in the analysis. Using the same methodology as in the previous aggregation, the estimate of the technological parameter $\beta_{i j}$ for Whites and the aggregate of all Non-Whites is 291.7 with the $z$ statistics of 12.3 , which is highly significant and in the range of the values estimated in Tables 6 and 8, where only a smaller sample of school districts was available. Given the similarity of the coefficients estimated in these restricted models to the baseline estimates, it turns out that aggregation strengthens the main prediction of the baseline analysis that non-White and White labor is complementary. ${ }^{26}$ These results also suggest, although this deserves further research, that one should not expect markedly different prediction in this respect by aggregating and disaggregating non-White ethnic groups, for example Asians into Japanese, Chinese, Vietnamese, and other Asian ethnicities.

\subsection{Non-Labor Inputs}

As mentioned above, land, capital, and technology typically enter production, alongside labor. Unfortunately, it is impossible to obtain measures of technology and the measures of land and capital are scarce and problematic. Nevertheless, I test the robustness of the baseline predictions with respect to inclusion of variables measuring urbanization and farming intensity, which are, by assumption, correlated with the use of capital, land, and technology in production. Urbanization and farming intensity are measured as the shares of inhabitants of a school district residing in urban and farm areas, respectively. Similarly as in the case of educational variables, the fixed effects formalization is adopted such that a vector of measures of non-labor inputs is directly introduced into the econometric model (3). Again, the Zellner's SUREG estimator is used and $\beta_{i j}=\beta_{j i}$ is imposed.

\footnotetext{
${ }^{26}$ Given the data available, aggregation also permits 3SLS estimation with the values of the shares of Blacks and all other non-White ethnic groups together in the population from the year 1870 as instruments. This yields the estimate of $\beta_{i j}$ for Whites and Non-Whites of 363.7 with the z statistics 14.4. This result further supports the complementarity prediction and suggests that even if there was an endogeneity bias, it would work against the complementarity hypothesis and, because of this, the presented estimates of $\beta_{i j}$ are conservative in this respect.
} 
Table 10: Non-labor inputs in production.

\begin{tabular}{|c|c|c|c|c|c|c|}
\hline & \multicolumn{6}{|c|}{ Median earnings of group i, full-time workers } \\
\hline$X_{j} / X_{i}$ & (1) & (2) & (3) & (4) & (5) & (6) \\
\hline $\mathrm{Y}_{j}{ }^{i}$ & White & Black & $\begin{array}{c}\text { American } \\
\text { Indian }\end{array}$ & Asian & $\begin{array}{c}\text { Pacific } \\
\text { Islanders }\end{array}$ & $\begin{array}{c}\text { Hispanic or } \\
\text { Latino }\end{array}$ \\
\hline White & & & & & & \\
\hline Black & $\begin{array}{c}164.1 \\
(4.6)^{* *}\end{array}$ & & & & & \\
\hline American Indian & $\begin{array}{c}161.8 \\
(4.2)^{* *}\end{array}$ & $\begin{array}{l}-72.7 \\
(1.0)\end{array}$ & & & & \\
\hline Asian & $\begin{array}{c}327.5 \\
(5.8)^{* *}\end{array}$ & $\begin{array}{c}-139.1 \\
(1.4)\end{array}$ & $\begin{array}{l}46.2 \\
(0.4)\end{array}$ & & & \\
\hline Pacific Islanders & $\begin{array}{c}62.1 \\
(2.0)^{*}\end{array}$ & $\begin{array}{l}-73.6 \\
(1.4)\end{array}$ & $\begin{array}{l}52.7 \\
(0.2)\end{array}$ & $\begin{array}{c}468.0 \\
(3.6)^{* *}\end{array}$ & & \\
\hline Hispanic or Latino & $\begin{array}{c}217.2 \\
(4.5)^{* *}\end{array}$ & $\begin{array}{l}-12.9 \\
(0.2)\end{array}$ & $\begin{array}{l}223.1 \\
(2.1)^{*}\end{array}$ & $\begin{array}{l}166.0 \\
(1.2)\end{array}$ & $\begin{array}{l}-33.2 \\
(0.5)\end{array}$ & \\
\hline Non-Labor Inputs: & & & & & & \\
\hline Farming Intensity & $\begin{array}{l}-25,048 \\
(2.5)^{*}\end{array}$ & $\begin{array}{l}42,615 \\
(2.7)^{* *}\end{array}$ & $\begin{array}{l}-43,870 \\
(2.3)^{*}\end{array}$ & $\begin{array}{c}31,056 \\
(1.6)\end{array}$ & $\begin{array}{c}-33,007 \\
(1.2)\end{array}$ & $\begin{array}{l}-37,919 \\
(3.2)^{* *}\end{array}$ \\
\hline Urbanization & $\begin{array}{l}702 \\
(1.0)\end{array}$ & $\begin{array}{l}1,641 \\
(1.5)\end{array}$ & $\begin{array}{c}-2,437 \\
(1.8)\end{array}$ & $\begin{array}{l}2,869 \\
(2.0)\end{array}$ & $\begin{array}{l}-2,773 \\
(1.4)\end{array}$ & $\begin{array}{l}-413 \\
(0.5)\end{array}$ \\
\hline Constant & $\begin{array}{l}15,458 \\
(5.8)^{* *}\end{array}$ & $\begin{array}{c}23,109 \\
(13.8)^{* *}\end{array}$ & $\begin{array}{c}22,274 \\
(11.5)^{* *}\end{array}$ & $\begin{array}{l}12,844 \\
(5.5)^{* *}\end{array}$ & $\begin{array}{c}25,323 \\
(10.1)^{* *}\end{array}$ & $\begin{array}{c}17,867 \\
(15.1)^{* *}\end{array}$ \\
\hline R-squared & 0.65 & 0.33 & 0.16 & 0.36 & 0.13 & 0.36 \\
\hline Observations & 1943 & 1943 & 1943 & 1943 & 1943 & 1943 \\
\hline $\begin{array}{l}\text { Absolute value of } \mathrm{z} \\
\text { * significant at } 5 \text { pe }\end{array}$ & $\begin{array}{l}\text { ics in pa } \\
* * \text { signi }\end{array}$ & 1 percen & & & & \\
\hline
\end{tabular}

Table 10 summarizes the results. One observes that inclusion of the two variables that measure farming intensity and urbanization does not change the estimates of the technological parameters significantly, as compared to the baseline model of Table 6 . This result supports the robustness of the baseline estimates vis-à-vis presence of nonlabor inputs. Both of these variables are significant, however (even for urbanization, which is typically only marginally significant in each regression, exclusion is rejected). Further improvement of the measures of non-labor inputs is necessary in future research, however. 


\section{Constant Elasticity of Substitution}

Aggregation of non-White workers into one category yields another interesting possibility. Namely, it permits econometric analysis of a two-factor constant elasticity of substitution (CES) model of labor market competition. ${ }^{27}$ In this section I estimate the elasticity of substitution between labor of the White ethnic group and the aggregate of the labor input of all non-White ethnic groups but Pacific Islanders, similarly as in Section 5.2. For this purpose, assume that production takes place according to the CES production function:

$C=\left(\left(\int_{0}^{I} X_{i} d i\right)^{(\rho-1) / \rho}+\left(\int_{0}^{J} X_{j} d j\right)^{(\rho-1) / \rho}\right)^{\rho /(\rho-1)}$,

where $\rho>0$ denotes the elasticity of substitution between non-White and White labor. Assuming a competitive labor market, from this specification it follows that $W_{i} / W_{j}=\left(X_{j} / X_{i}\right)^{\frac{1}{\rho}}$. Taking the logarithm of both sides and assuming that all factors affecting relative wages in labor market $n$ other than $X_{j, n} / X_{i, n}$ are fully accounted of by the fixed-effects approach described in Section 2, one obtains a CES econometric model: $\operatorname{Ln}\left(E_{i, n} / E_{j, n}\right)=\gamma_{0}+\gamma_{i j} \operatorname{Ln}\left(X_{j, n} / X_{i, n}\right)+\gamma_{1} Z_{n}+\varepsilon_{n}$

where $Z_{n}$ is the vector of factors affecting production and relative wages in particular in labor market $n$ and $\gamma_{i j}$ is the elasticity parameter of our interest that has a convenient interpretation: it is the inverse of the elasticity of substitution $\rho$.

Table 11 summarizes the results of estimation of the CES econometric model (4). ${ }^{28}$ Column (1) presents the OLS estimate of the coefficient $\gamma_{i j}$ equal to 0.0387. It is significant at any conventional significance level and its magnitude implies the elasticity of substitution of 25.8. To investigate the possibility of endogeneity bias, a two-stage least square estimator was computed using the past values of the ratio of White and nonWhite populations as instruments from the year 1990. The results summarized in column

\footnotetext{
${ }^{27}$ The nonlinearity of the multiple-factor CES models complicates econometric analysis such that conventional estimation methods are unusable.

${ }^{28}$ As above, coefficients with education variables and regional dummies are not reported.
} 
(2), given their similarity to those in column (1), suggest that the possible endogeneity bias is not severe and that the elasticity of substitution between non-White and White labor is about $25 .^{29}$

Table 11: Constant elasticity of substitution.

\begin{tabular}{|l|c|c|}
\hline & \multicolumn{2}{|l|}{$\begin{array}{l}\text { Logarithm of the White/non-White ratio of } \\
\text { median earnings, full time workers }\end{array}$} \\
\hline & $(1)$ & $(2)$ \\
\hline Logarithm of the White/non-White ratio of full-time & 0.0387 & 0.0392 \\
workers & $(16.7)^{* *}$ & $(15.3)^{* *}$ \\
\hline R-squared & 0.27 & 0.27 \\
Observations & 9042 & 8304 \\
\hline Robust t statistics in parentheses & & \\
$*$ significant at 5 percent; ** significant at 1 percent & & \\
\hline
\end{tabular}

The main message of this section is that it confirms the results obtained in the generalized Leontief framework: non-White (White) relative wage is increasing in the relative number of White (non-White) workers in the local labor market. In other words, it corroborates the finding that White/non-White wage differential is increasing in the share of non-White workers in production. It is difficult to compare the magnitudes of the present results with those of Sections 4 and 5, especially because the cross elasticities of substitution are not constant. One result is robust, however: a relatively large change in labor supplies corresponds to a relatively small change in wages. ${ }^{30}$ To conclude, the estimation of the CES model further supports the hypothesis that non-White and White labor is not perfectly substitutable. Furthermore, it suggests that the empirical evidence that it hurts to be a member of a large ethnic group in terms of relative earnings is, at least partly, a labor market phenomenon.

\footnotetext{
${ }^{29}$ The model was estimated also using the 1870 White/non-White population ratio as instrument, yielding the estimate of $\gamma_{i j}$ equal to 0.109 with the $z$ statistics of 7.9, implying the elasticity of substitution of 9.2. This result further supports that there is imperfect substitutability between non-White and White labor and suggest that the estimates of the elasticity of substitution of Table 11 are conservative.

${ }^{30}$ Assuming that the White/non-White earnings differential is fully explained by non-White percentage, computations show that according to the CES specification and the estimated elasticity coefficient of about 0.04 , White/non-White earnings differential is by about one quarter smaller in school districts with nonWhite population 0.9 percent than in those with 19.9 percent of non-White workers. This example suggest that the results of this section are comparable to those based on the generalized Leontief production function, see the example at the end of Section 4.
} 


\section{Conclusion}

Using data from the US labor market, this empirical paper sheds light on the substitutability of labor of non-White and White ethnic groups. In particular, in the generalized Leontief framework, it is empirically established that non-White and White labor exhibit complementarity in production. This result suggests that the findings of the large body of empirical literature that observes a negative relationship between nonWhite relative earnings and non-White concentration in a local labor market is a labor market phenomenon. In particular, based on this result it can be argued that concentration of non-White workers in the local labor market has a direct and causal negative effect on non-White relative wage due to complementarity of non-White and White labor in production. Moreover, complementarity of White and non-White labor in production suggests that ethnic diversity of labor force has positive effects on aggregate output. That labor market competition between non-White and White workers generates a negative relationship between relative earnings of non-White workers and their proportion in the local labor market is corroborated in the CES framework.

Two issues should be noted concerning the results of this study. First, in the light of earlier studies it appears that the definition of social groups competing in the labor market may affect the result as concerns the estimates of the substitutability of labor. In particular, while this study suggests that non-White labor is complementary to White labor, other studies show that some subgroups of non-White and White populations, including immigrants, youths, or women, may be substitutes in production. Certainly, the particular partition of the labor force that one adopts is determined by the focus of the particular study. In any case, further research is necessary to elucidate the substitutability of labor of different subgroups of non-White and White workers. Second, it is desirable to study the supply side of the labor market in a greater detail. Certainly, one would like to understand the processes that determine the supply of labor in a local labor market as determined by migration and individual labor supply decision, so that a richer account can be taken of the wage determination process. 
Based on the results of this study, it is apparent that the established labor market effects should be evaluated in the context of long-run rather than short-run migration. In particular, the estimated elasticities of complementarity (substitution) between non-White and White workers are relatively small and thus short-run migration should not be expected to affect White/non-White earnings inequality significantly. On the other hand, the study demonstrates that long-run migration patterns that generate substantial variation in ethnic composition of labor markets may significantly affect interethnic earnings distribution. 


\section{References}

Altonji, J. and R. Blank, "Race and Gender in the Labor Market”, in eds. O.Ashenfelter and D. Card, Handbook of Labor Economics, Volume 3c, (1998).

Arrow, Kenneth J., "Models of Job Discrimination," in A. H. Pascal, ed. Racial Discrimination in Economic Life, Lexington, Mass: D.C. Heath, (1972a), pp. 83-102 Arrow, Kenneth J., "Some Mathematical Models of Race Discrimination in the Labor Market," in A. H. Pascal, ed. Racial Discrimination in Economic Life, Lexington, Mass: D.C. Heath, (1972b), pp. 187-204.

Arrow, Kenneth J., “The Theory of Discrimination,” in Orley Ashenfelter and Albert Rees, eds. Discrimination in the Labor Markets, Princeton, N.J.: Princeton University Press, (1973), pp. 3-33.

Arrow, Kenneth J., "What Has Economics to Say about Racial Discrimination?” (Symposium: Discrimination in Product, Credit and Labor Markets), The Journal of Economic Perspectives, Vol. 12, No. 2. (Spring, 1998), pp. 91-100.

Becker, Gary, The Economics of Discrimination, Chicago: University of Chicago Press, (1957).

Blalock, H.M., Jr., “Economic Discrimination and Negro Increase,” American Sociological Review, Vol. 21, No. 5. (Oct., 1956), pp. 584-588.

Blalock, H.M., Jr., "Per Cent Non-White and Discrimination in the South,” American Sociological Review, Vol. 22, No. 6. (Dec., 1957), pp. 677-682.

Borjas, George J., "The Substitutability of Black, Hispanic, and White Labor,” Economic Inquiry, Vol. 21, (January (1983), pp. 93-106.

Borjas, George J., “Immigrants, Minorities, and Labor Market Competition,” Industrial and Labor Relations Review, Vol. 40, No. 3, (April 1987), pp. 382-392.

Borjas, George J., "Long-Run Convergence of Ethnic Skill Differentials: The Children and Grandchildren of the Great Migration,” Industrial and Labor Relations Review, (July 1994), pp. 553-573.

Brown, David L. and Glenn V. Fuguitt, "Percent NonWhite and Racial Disparity in Nonmetropolitan Cities of the South,” Social Science Quarterly, Vol. 53 (December, 1972), pp. 573-82.

Chiswick, Barry R., "Differences in Education and Earnings across Racial and Ethnic Groups: Tastes, Discrimination, and Investments in Child Quality,” The Quarterly Journal of Economics, Vol. 103(3), (1988), pp. 571-97.

Diewert, W. E., “An Application of The Shephard Duality Theorem: A Generalized Leontief Production Function,” Journal of Political Economy, Vol. 79, (1971), pp. 481507.

Frisbie, W. Parker and Lisa Neidert, "Inequality and the Relative Size of Minority Populations: A Comparative Analysis,” The American Journal of Sociology, Vol. 82, No. 5. (Mar., 1977), pp. 1007-1030.

Grant, James H. and Daniel S. Hamermesh, "Labor Market Competition among Youths, White Women and Others," The Review of Economics and Statistics, Vol. 63, No. 3, (Aug. 1981), pp. 354-360. 
Grossman, Jean Baldwin, "The Substitutability of Natives and Immigrants in Production,” The Review of Economics and Statistics, Vol. 64, No. 4, (Nov. 1982), pp. 596-603.

Heer, David M., “The Sentiment of White Supremacy and Ecological Study," The American Journal of Sociology, Vol. 64, No. 6, (May, 1959), pp. 592-598.

Hicks, John, "Elasticity of Substitution Again: Substitutes and Complements," Oxford Economic Papers, Vol. 22, No. 3, (Nov. 1970), pp 289-96.

Hofstede, Geert H., "Culture's Consequences: International Differences in Work-related Values. Beverly Hills,” California: Sage Publications, (1980).

Kahanec, Martin, "Social Interaction and the Minority-Majority Earnings Inequality: Why Being a Minority Hurts But Being a Big Minority Hurts More”, CentER Discussion Paper Nr. 41/2004, Tilburg University, (Oct. 2004)

Tienda, Marta and Ding-Tzann Lii, "Minority Concentration and Earnings Inequality: Blacks, Hispanics, and Asians Compared,” The American Journal of Sociology, Vol. 93, No. 1, (Jul. 1987), pp. 141-165.

\section{Appendix}

Table 1: The substitutability of ethnic labor - empirical evidence.

\begin{tabular}{|c|c|c|c|c|}
\hline Study & $\begin{array}{l}\text { Economet } \\
\text { ric Model }\end{array}$ & Data & $\begin{array}{c}\text { Estimated elasticities of factor prices: } \\
\text { The change in the wage of A with respect to } \\
\text { the change in the quantity of labor B }\end{array}$ & $\begin{array}{l}\text { Separability } \\
\text { of capital and } \\
\text { labor inputs }\end{array}$ \\
\hline $\begin{array}{l}\text { Grant and } \\
\text { Hamermesh } \\
\text { (1981) }\end{array}$ & Translog & $\begin{array}{l}1 / 1000 \text { Public Use } \\
\text { Sample of the } 1970 \text { US } \\
\text { Census }\end{array}$ & $\begin{array}{l}\text { Black to White female: } 0.0203 \\
\text { Black to White male: }-0.0536^{* *} \\
\text { White female to Black: } 0.0119 \\
\text { White male to Black: }-0.0055^{* *}\end{array}$ & Rejected. \\
\hline $\begin{array}{l}\text { Grossman } \\
(1982)\end{array}$ & Translog & 1970 US Census & $\begin{array}{l}\text { Second generation immigrants to natives: }-0.39^{* *} \\
\text { Foreign-born immigrants to natives: }-0.16^{* *} \\
\text { Natives to second generation immigrants: }-0.15^{* *} \\
\text { Natives to foreign-born immigrants: }-0.02^{* *}\end{array}$ & Not rejected. \\
\hline $\begin{array}{l}\text { Borjas } \\
(1983)\end{array}$ & $\begin{array}{l}\text { Generalized } \\
\text { Leontief }\end{array}$ & $\begin{array}{l}1976 \text { Survey of Income } \\
\text { and Education, } 5 / 100 \\
\text { Sample, US Census } \\
\text { Bureau. }\end{array}$ & $\begin{array}{l}\text { \$ Black to White: } 0.0026 /-0.0639 * * \\
{ }^{\$} \text { Hispanic to White: } 0.0234^{*} / 0.0353\end{array}$ & Not rejected. \\
\hline $\begin{array}{l}\text { Borjas } \\
(1987)\end{array}$ & $\begin{array}{l}\text { Generalized } \\
\text { Leontief }\end{array}$ & $\begin{array}{l}1980 \text { 5/100 A Sample, } \\
\text { US Census }\end{array}$ & $\begin{array}{l}{ }^{\dagger} \text { Black immigrants to White Natives: }-0.001 * * /-0.001 \\
{ }^{\dagger} \text { Hispanic immigrants to White Natives: }-0.002^{* * *} / 0.002 \\
{ }^{\dagger} \text { Asian immigrants to White Natives: }-0.002^{* * /-}-0.003 \\
{ }^{\#} \text { Black natives to White natives: }-1158.6^{* *} \\
{ }^{\#} \text { Hispanic natives to White natives: }-98.5 \\
{ }^{*} \text { Asian natives to White natives: }-120.0\end{array}$ & $\begin{array}{l}\text { No formal test } \\
\text { performed. } \\
\text { Significant } \\
\text { coefficients with } \\
\text { the capital input. }\end{array}$ \\
\hline \multicolumn{5}{|c|}{$\begin{array}{l}\text { Note: ** Significant at } 0.01 \text { significance level, * Significant at } 0.05 \text { Significance level. } \\
\$ \text { Elasticities of complementarity: The change in the relative wage of A with respect to the relative change in the quantity of B, holding the } \\
\text { marginal costs and quantities of other factors constant. OLS/IV estimates } \\
\text { \# Technology parameters. Negative (positive) sign implies substitutability (complementarity) of inputs. } \\
{ }^{\dagger} \text { OLS/IV estimate. }\end{array}$} \\
\hline
\end{tabular}

